\title{
KRAKOWSKIE DUCHOWIEŃSTWO PARAFIALNE PRZY KOŃCU ŚREDNIOWIECZA
}

W swych badaniach archiwalnych autor śledzi życie parafii krakowskich na przestrzeni całego wieku $\mathrm{XV}$. W tym szkicu jednak, ogranicza się tylko do przedstawienia duchowieństwa krakowskiego $w$ ostatniej ćwierci, to jest od momentu, w którym Jan Długosz w Liber Beneficionum ${ }^{1}$ zamkną opis parafii krakowskich.

W Krakowie, w obrębie murów miejskich, było 5 parafii, na Kazimierzu 3, na Kleparzu 1, na Zwierzyńcu 1 i na wschód od murów miejskich 1, zwana "za murami miasta". Dwie parafie - św. Anny i św. Floriana były akademickimi, dwie związane były z kolegiatami - św. Floriana i Wszystkich Świętych (od r. 1490), cztery zaś z klasztorami - św. Krzyża, św. Augustyna na Zwierzyńcu, Bożego Ciała na Kazimierzu oraz św. Stanislawa biskupa na Skałce. Główną, jednak parafią krakowską były Mariacka, na czele z jej archiprezbiterem. Do wielu parafii należały tereny i osiedla pozamiejskie. 1 tak do parafii Mariackiej - Bronowice ${ }^{2}$, do św. Krzyża - Prądnik Bialy ${ }^{3}$, do św. Szczepana zespół wsi zwanych Ogrodnikamił. Parafia zwierzyniecka posiadala wsie $w$ okolicy góry bielańskiej, a parafia na Skałce -

1 Jomnis Dhugosz senioris chnonici Crncovientsis Liber beneficionum diocesis Crucoviensis. T. 2, s. 1-28. Kraków 1864. Archidiaconatus Cracoviensis

2 Tamże, s. 23.

3 Tamże, t. 3, s. 24.

\& Tamże, t. 2, s. 14-16. - Do wsi, zamieszkalych przez podkrakowskich ogrodników, zwanych Ogrodnikami należaly: Kawiory, Czarna Wieś z Czarna ulica, Pólwsie, Nowa Wieś, Łobzów, a poza nimi Krowodrza, Biskupie, Mydlniki, Rzaska i Bronowice Niemieckie (Wielkie). Do tego dochodzity dwie osady: Garbary i Krupniki z ulica Krupnicza zwana Lutifigulorum.

5 Tamże, t. 3, s. 60, 62, 68-69. - Do parafii zwierzynieckiej, oprócz Zwierzyńca, należaly wsie: Olszanica, Zabierzów, Przegorzaly i Bielany. 
Dębniki ${ }^{6}$ i wsie sąsiednie, św. Jakuba na Kazimierzu - okolice Kopca Krakusa ${ }^{\overline{ }}$, zaś do parafii św. Mikolaja należalo pobrzeże rzeki Pradnik ${ }^{b}$.

Wśród duchowieństwa parafialnego krakowskiego poczesne stanowisko zajmował archiprezbiter Mariacki, Jerzy Sworcz (od r. 1450), równocześnie posiadający prałature dziekana iv kolegiacie Sandomierskiej ${ }^{9}$. Zarządzanie kościolem i parafią nie bylo latwe. W tym czasie trwala właśnie budowa wielkiego oltarza Wita Stwosza (1477-1489) oraz nowych organów ${ }^{10}$, poza tym Sworcz prowadzil wiele sporów o dziesięciny, np. w l. 1484-1486 z Marcinem opatem mogilskim o dochody z Winiar kolo Dobczyc ${ }^{17}$. Pod koniec swego urzedowania ufundował Ogrojec przy kościele Sw. Barbary (r. 1490). Kiedy iv r. 1493 splonęly zabudowania plebanii ${ }^{12}$, archiprezbiter byl już tak chory, że nie czul się na silach aby prałatówkę odbudować, toteż zrezygnował ze swej funkcji. W rok później zmarł (1494) ${ }^{\text {l3 }}$. W kościele Mariackim, w kaplicach i obok filarów stalo mnóstwo ol tarzy, przy których odprawiali msze święte zastępcy altarystów, zwani lectores missarmm. Księża gracjaliści służyli bractwom i cechom miejskim, sprawowaniem sakramentów zajmowali się wikarzy, wśród których szczególnie Wyróżniał sie Jerzy z Lańcuta ${ }^{14}$. W parafii śpiewaly dwa kolegia mansjonarzy jedno w chórze kościoła Mariackiego, drugie w kościele Św. Barbary. Nad tą sporą liczbą księży czuwal wicepleban Stanisław Stano i wicezakrystianin Stanislaw z Piotrkowa ${ }^{15}$, a od r. 1491 Marcin z rodziny Macieja Mydlarza ojca Stanisława późniejszego opata mogilskiego ${ }^{16}$. Nastẹpcą Sworcza został Jan

6 Tamże, t. 3, s. 116-118. - Do parafii na Skalce naleźaly miejscowości: Pobrzezie nad brzegiem Wisly, Folwarki na brzegu Wilgi, Blonie pod kopcem Krakusa, Dębniki, Kobierzyn, Pychowice i część Kazimierza.

7 Tamże, t. 2, s. 22-26. - Do parafii św. Jakuba przylączone byly: Wróblowice, Kurdwanów, Wola Duchacka, Jugowice, Plaszów, Prokocim, Rząska, Borek Falęcki, Lagiewniki, Swoszowice.

8 Tamże, t. 2, s. 27-28. - Parafia św. Mikolaja obejmowala przedmieście przed Bramą Mikolajska zwane później Wesola, Piasek, Grzegórzki, Prądnik (Czerwony) i Dąbie. A także Gląbinów, Leg, Rybitwy.

9 Acta Officialia (Offic. Crac.) w Archiwum Kurii Metropolitalnej w Krakowie, 3, s. 279, 400, 423, 430-431, 465, 515, 693; Offic. Crac. 11, s. 173; Offic. Crac. 13, s. 1043 Offic. Crac. 14, s. 813. Jerzy Sworcz posiadal kapelana księdza Stanislawa - Offic. Crac. 3, s. 258. Jego gospodarstwem domowym zarzadzal ks. Jan z Biecza - Offic. Crac. 11, s. 283. Do świeckiej slużby należal Wojciech z Dębicy - Offic. Crac. 2, s. 346 i Stefan - Offic. Crac. 11, s. 210.

10 Na organach gral organista Mikolaj, który do obsługi instrumentu utrzymywal 10 kalikantów - Offic. Crac. 2, s. 526, 528, 542.

1 Offic. Crac. 11, s. 24, 31-34, 41, 47-49, 51, 52a, 61, 74-77. Prowadzil sprawy procesowe z Janem Wątróbka, kanonikiem krakowskim w sprawie spadku po śmierci Jana Lutka - Offic. Crac. 2, s. 786, z Wojciechem z Solca, wikarym katedralnym - Offic. Crac. 2, s. 657; 18, s. 388 oraz $\mathrm{z}$ Janem Plechowskim, kanonikiem skalbmierskiem, plebanem w Więclawicach - Offic. Crac. 2, s. $672,677,682,769,770,784,793 ; 18$, s. 282.

12 Offic. Crac. 15 , s. 12.

13 Offic. Crac. 18, s. 106-107, 238, 240.

14 Offic. Crac. 13, s. 1119.

15 Offic. Crac. 18, s. 299. Obydwaj byli egzekutorami testamentu Sworcza. 
Borzymowski ${ }^{17}$ h. Kopacz, kanonik krakowski (1485), dotychczasowy żupnik obojga salin królewskich (1489-1493). Po pięciu latach rządów zmarł on w r. $1498^{18}$. Wtedy wakującą plebanię Mariacką objąl Jan Heydecke ${ }^{19}$ de Damnis (z Dąbia kolo Szczecina) używający przydomku Mirica, najpierw wicenotariusz miasta Krakowa, a po śmierci Krzysztofa Rebencza, pisarz miejski (1481). Mirica zmarl w r. 1512. Od pólnocnowschodniej strony kościoła Mariackiego rozciągała się parafia św. Ducha, oddana w r. 1244 przez biskupa krakowskiego Prandotę pod opiekę zakonu szpitalników Św. Ducha. Prepozyt szpitala byl zarazem rządca parafii. Do opieki nad szpitalem miał pomocnika magistra hospitalis, który równocześnie sprawowal opiekę duszpasterska nad chorymi. W kościele parafialnym o porządek nabożeństw dbal zakrystianin, kazania głosil kaznodzieja a spowiedzi słuchal confessor. Bardzo zasłużonym dla parafii byl prepozyt Mikołaj z Opawy ${ }^{20}$ w diecezji Olomunieckiej. W r. 1574 od strony Szpitalnej tuż obok szpitala zbudowal, on dom murowany w miejsce drewnianej szkoły. Znajdowaly się $w$ nim na parterze mieszkanie dla rektora i sala, w której uczyła się mlodzież, a na górze mieszkania dla scholarów. Aby podnieść splendor swego zakonu Mikolaj z Opawy postarał się (1481) o przywilej noszenia almutium ${ }^{21}$ na wzór archiprezbitera Mariackiego. W r. 1483 Mikolaj zrezygnowal z prepozytury, a jego miejsce zajal Marcin z Biecza ${ }^{22}$, który pelnil ten urzad do r. $1500^{23}$. Szpital, którym zarządzali prepozyci duchaccy nie był zwykłym przytułkiem dla biedoty i chorych, jak to bywało $w$ innych parafiach, ale jedynym w Polsce zakladem leczniczym, do którego zachodzil lekarz, doktor medycyny Jan Bar (Ursinus) $^{24}$ a lekarstwami slużyl mu aptekarz, Marcin Kromer ${ }^{25}$. W r. 1500 stanowisko prepozyta objął Jan z Lańcuta ${ }^{26}$. Parafia św. Szczepana przylegała do Mariackiej od zachodu. Zarządzał nią magister Florian, prebendarz królowej Zofii ${ }^{27}$. Byla to parafia duża i wymagająca wiele pracy, gdyż oprócz części miejskiej należaly do niej Garbary, Bronowice Niemieckie (Wielkie), zespól wsi

16 Offic. Crac. 3, s. 546.

17 Offic. Crac. 14, s. 911 ; 15, s. 351, 355, 560-561, 567, 577. - Przed śmiercią staral się o prebendę św. Marcina w Krakowie, na która byl prezentowany. - Offic. Crac. 3, s. 38; 17, s. 496; 20, s. $149,428$.

16 Offic. Crac. 15 , s. 584, 586; 20, s. 429. - Egzekutorami jego testamentu byli Mikolaj Lącki, kanonik krakowski i Jakub z Lublina, kanonik kielecki.

19 Offic. Crac. 20, s. 410,537,549;21, s. 477. - Osiagnąwszy ta godność zrezygnowal z altarii św. Piotra i Pawla, jaka posiadal w kościele Św. Szczepana w Krakowie. - Offic. Crac. 3, s. 221; 20 , s. 410 .

20 Offic. Crac. 2, s. 561, 564, 591, 616, 618, 621, 627, 630, 636.

21 Archiwum Kapituly Metropolitalnej w Krakowie (Capit. Crac.). Rkp. Acta capitularia, t. 2, k. $162,168$.

22 Archiwum Kurii Metropolitalnej w Krakowie (Episc. Crac.). Rkp. Acta Episcopalin, t. 3, k. 255.

23 Offic. Crac. 11 , s. $39,168,188,200 ; 14$, s. $54,106,426$.

24 Offic. Crac. 18 , s. 541 .

25 Offic. Crac. 18a, s. 145.

26 Offic. Crac. 17 , s. 709,$715 ; 20$, s. 627.

27 Offic. Crac. 21 , s. $9 ; 2$, s. $337,345,400,820 ; 3$, s. $185,248$. 
zwanych Ogrodnikami (Czarna Wicś, Nowa Wieś, Łobzów, Mydlniki) ${ }^{28}$. Piecza nad tak rozległymi dobrami pochłaniała mu tak dużo czasu, iż zaniedbywał swe obowiązki w kaplicy wawelskiej. Z tego powodu byl wielokrotnie upominany ${ }^{29}$ przez kapitulę. Zmarl wr. $1484^{30}$, jego prebendę katedralną otrzymał magister Mikolaj Czepel, natomiast plebanię parafii św. Szczepana powierzono lekarzowi, magistrowi medycyny Janowi Wels (Welsch, Velze) $)^{3 !}$. On też był wykonawca testamentu zmarlego mgr Floriana (1485) ${ }^{32}$. Wels byl także altarysta wawelskim. $Z$ powodu wielorakich zajęć - lekarza, plebana, wykladowcy - potrzebowal pomocy przy prowadzeniu parafii. Jego wikarym zostal Stanisław z Pilzna ${ }^{33}$ a zakrystianinem Piotr z Kwieciszowa ${ }^{34}$. W r. 1496 prosil Wels Imrama Salomona o darowanie parafij św. Szczepana gruntu za murami miasta na zalożenie nowego cmentarza, gdyż stary, przykościelny, znajdujacy się na obecnym placu Szczepańskim, był już zupelnie zapelniony. W zamian przyjal zobowiązanie do odprawiania mszy za duszę fundatora (tzw. anniwersarz) ${ }^{35}$. Wkrótce wywiązal się spór między parafią a sąsiadującym z cmentarzem klasztorem karmelitów na Piasku ${ }^{36}$, ciągnący się jeszcze w czasie urzędowania jego następcy Grzegorza Ostrowskiego. Jan Wels zmarl w r. 1498, ustanowiwszy przedtem egzekutorów swego testamentu w osobach Marcina z Krakowa i Michala Paryskiego ${ }^{37}$.

Dla parafii przy uniwersyteckim kościele Św. Anny plebanów wybierało kolegium Akademii. Po Janie Progarze (zm. 1471) i jego następcy Janie Koczwarze (1471-1472) zarzad parafii otrzymal Maciej z Kościana, doktor dekretó $w^{38}$. Oprócz plebanii św. Anny posiadal altarię w kaplicy zwanej Białuszyną albo Lubelczyków (obecnie Potockich) ${ }^{39}$ na Wawelu. Maciej, w r. 1475, zaczał spisywać nadzwyczajne lasiki otrzymywane przez lud od zmarłego przed dwoma laty (24 XII 1473) profesora teologii w Uniwersytecie Krakowskim Jana $z$ Kęt. Spis ten, dokonywany w obecności wiarygodnych świadków, prowadzil aż do 26 listopada 1483 roku ${ }^{40}$. Po śmierci Macieja ${ }^{4 !}$ kolegiaci prezentowali na to stanowisko Jana z Wysokiej (1488). Przeciw tej decyzji zaprotestowal, odwolujac się do Stolicy świętej, Bartlomiej ze Żnina,

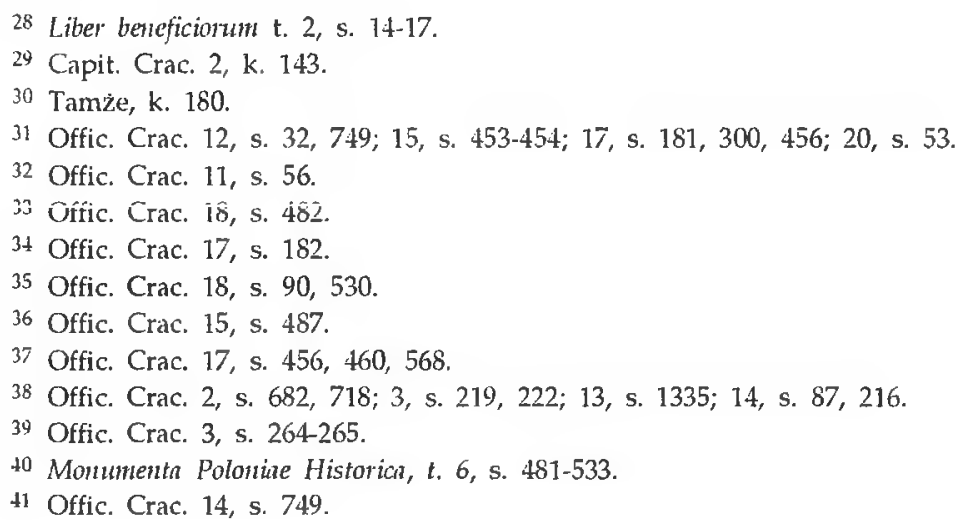


znany ze swego niespokojnego charakteru ${ }^{+2}$. Kolegiaci sklonili go jednak, by apelację wycofal, obiecując $w$ zamian plebanię św. Anny. Bartlomiej przyjął te propozycje, zrezvgnowal $z$ kolegiatury $\mathrm{i}$ wszedł $w$ zarząd parafii ${ }^{43}$.

$Z$ uniwersytetem związana była także parafia św. Floriana na Kleparzu. Zarzadzal parafia prepozyt tamtejszej kolegiaty, mianowany nie przez Uniwersytet, lecz przez króla. Prepozytura tej kolegiaty byla bogato uposażona, dlatego ubiegali się o nią wysocy dostojnicy państwa. Od r. 1451 mimo przeszkód ze strony samego ordynariusza kardynala Zbigniewa Oleśnickiego posiadał ja Jakub Koniecpolski, h. Pobóg ${ }^{4 t}$, syn kanclerza Jana Taszki z Koniecpola i Doroty Sieneńskiej, kuzynki kardynala. Jakub równocześnie dzierżył świecki urząd starosty sieradzkiego, związany z jego rodziną. Zmarl on w r. 1481, jego następca został Grzegorz z Lubrańca, h. Godziemba ${ }^{45}$, który jako wicekanclerz państwa niewiele czasu mógł poświęcać życiu parafii. Mimo tego życie religijne bylo ożywione, gdyż kapitułę stanowili kanonicy będacy przeważnie profesorami Uniwersytetu Krakowskiego.

Na wschód od Krakowa i parafii św. Floriana za murami miasta, stal kościół św. Mikolaja; należąca doń parafia byla zarządzana przez Grzegorza z Chmielnika ${ }^{46}$. Prezentowało go na tę funkcję opactwo tynieckie, które mialo prawo patronatu nad ta parafia. Gdy w r. 1453, Grzegorz zmarł, ówczesny opat tyniecki Maciej Skawinka wniósł prośbe do papieża Kaliksta III o inkorporację parafii św. Mikolaja do dóbr klasztoru tynieckiego. Prośba zostala załatwiona przychylnie $25 \times 1455$ r., lecz wydaje się, że konwent nie okazywal wielkich chęci do pracy duszpasterskiej przy tym kościele. Rok później opat zrzekł się nie tylko kościoła, ale i prawa patronatu nad ta parafia na rzecz Uniwersytetu Krakowskiego (r. 1456). Wyznaczony przez benedyktynów na plebana Rafal ze Skawiny musial ustapić. W r. 1462 z prezenty Uniwersytetu objąl zarząd parafii św. Mikolaja Andrzej Grzymała z Poznania ${ }^{47}$. W r. 1465 wybrano go na rektora Almae Universitatis Studii Cracoviensis, niestety $w$ czasie drugiej kadencji, latem roku 1466, zmarl na skutek szalejącej w mieście zarazy. Po nim aż do r. 1472 plebanem był Jan ze Slupcy ${ }^{4 \delta}$, profesor teologii, który po świętym Janie Kantym wzial kantorię kolegiaty św. Floriana $\mathrm{i}$ związana $\mathrm{z}$ ta kolegiata plebanię $w$ Olkuszu. Następnie po nim plebanem zostal Jan z Oświęcimia starszy, zwany Beberem. Profesor Uniwersytetu, w r. 1483 jego rektor, równocześnie doskonale zarządzał parafia

\footnotetext{
42 Offic. Crac. 14 , s. $538 ; 16$,. s. 144,$683 ; 18$, s. 603 :

43 Offic. Crac. 11, s. 222, 223, 225.

${ }^{H}$ Offic. Crac. 2, s. 470, 796, 824; Capit. Crac. 2, k. 159, 161; Pieradzka, PSB, t. 13, s.

45 Offic. Crac. 14 , s. 256,$748 ; 16$, s. 67 ; Pieradzka, PSB, t. 18 , s. $80-81$.

46 Offic. Crac. 1, s. 235, 239; 9, s. 497, 596.

17 Offic. Crac. 12, s. 53, 526, 584, 698; Birkenmajer, PSB, t. IX, s. 114-116.

48 Offic. Crac. 12, s. 20, 1027; Siemiatkowska, PSB, t. 10, s. 476-478.
} 517-519. 
św. Mikolaja aż do śmierci w r. 1494 $\$$. Kardynal Fryderyk Jagiellończyk, korzystając $\mathrm{z}$ wakatu, chcial obsadzić parafię swoim kandydatem Janem Salomonowiczem, lecz Akademia stanęla $w$ obronic swego patronatu i prezente otrzymal Jan (mlodszy) z Oświęcimia, zwany Sacranus ${ }^{50}$, który zarządzal parafią do r. 1502, będąc równocześnie wykonawcą testamentu swego poprzednika. Następca jego zostal Jan Amicinus, profesor i sufragan krakowski.

W zakolu Wisły, u stóp Wawelu znajdowala się parafia Wszystkich Siviętych. Urzędowało $w$ niej dwóch plebanów. Jednego $z$ nich nazywano plebanem domus muratae, mieszkal bowiem $w$ domu murowanym, mial za patronów rodzinę Tarnowskich, byl dziedzicem Podskalan kolo Modlnicy. Drugi, mieszkający $w$ domu drewnianym, mial za patronów dziedziców Slupowa kolo Działoszyc. Jego źródlem utrzymania byly Przegorzaly kolo Krakowa. Po śmierci Mikolaja Spiczmeri doktora "decretorum", na plebanię domus muratae był prezentowany w r. 1472 przez Jana Feliksa z Tarnowa, kasztelana wiślickiego, Jan Rafal Tarnowski ${ }^{51}$ kanonik krakowski. Plebanem domu drewnianego był Arnolf z Mierzyńca ${ }^{52}$, utriusque facultatis - doktor świętych kanonów i teolog, kanonik krakowski.

W roku 1490, kardynal Fryderyk Jagiellończyk erygowal przy kościele Wszystkich Świętych kolegiatę, dając plebanowi domu murowanego tytuł prepozyta, a plebanowi rezydencji drewnianej dziekana. Altaryści kościola zostali kanonikami kolegiaty. Prepozyturę otrzymał Mikolaj Wróblewski (zm. $1508)^{53}$, a dziekanię Stanisław Zelik doktor medycyny ${ }^{5: 4}$.

Na Kazimierzu, w południowo-zachodnim zakatku miasta, blisko murów obronnych polożona byla parafia św. Jakuba. Zalożona przez ród Strzemieńczyków, posiadała dwóch plebanów, prebendarza i altarię. Ostatnimi plebanami mediae partis byli Mikolaj z Przewieczerzyna ${ }^{55}$ notariusz kapituly krakowskiej (1452-1472) i Jakub Ryncza z Batowic ${ }^{56}$. W r. 1473 nastapiła zmiana organizacji parafialnej $w$ kościele Św. Jakuba. Zniesiono dwoistość rektoratu parafii, pleban Jakub Ryncza otrzymal tytul prepozyta, a w miejsce rektora alterinls partis utworzono cztery mansjonarie. Ten stan podaje Jan Długosz w Liber beneficiornm, co świadczy o tym, że opis parafii św. Jakuba zostal dokonany po roku 1473. Gdy w r. 1493 zmarł Jakub Ryncza o parafię ubiegalo się dwóch kandydatów, Jakub Trzecieski i Mikołaj Wróblewski ${ }^{\breve{f}}$.

\footnotetext{
12 Offic. Crac. 2, s. 400, 720, 307,3 , ง. $45,441,17$, s. $156 ; 18$, s. 538.

50 Offic. Crac. 3, s. 144, 161, 178, 201, 233, 249; 15, s. 395, 570; 16, s. 229; 17, s. $156,481$.

51 Epis. Crac. 3, k. 74, 78; Offic. Crac. 13, s. 587.

52 Epis. Crac. 3, k. 363; Offic. Crac. 11, s. 249, 287; 13, s. 1130; 14, s. 68, 118, 234, $262,387$.

53 Offic. Crac. 18, s. $578,583,586$.

54 Offic. Crac. 18 , s. 350.

55 Offic. Crac. 12, s. 107, 223, 365.

56 Offic. Crac. 13, s. 74, 643, 689, 700.

57 Offic. Crac. 18, s. 185, 208, 235, 300.
} 
Obaj, w wyniku sporu wycofali swoje kandydatury, miejsce prepozyta zają ostatecznie Marcin z Piotrkowa, bakałarz ${ }^{58}$. W roku 1495 wrócil na to stanowisko ponownie Mikolaj Wróblewski ${ }^{59}$.

Druga z parafii kazimierskich, św. Stanisława, znajdowała się na Skalce, znana byla szeroko z czci oddawanej św. Stanislawowi biskupowi. Zaslynęli tu dwaj plebani - Parkoszowie. Znany byl także ostatni pleban Jan Skalka ze Szebni, który odmówił zrzeczenia się parafii gdy Jan Dlugosz chcial osadzić tu zakon pustelników św. Pawla reguly św. Augustyna, czyli paulinów. Zrezygnowal dopiero wówczas, gdy Dlugosz zrzekł się na jego korzyść dwóch bogatych kanonii - sandomierskiej zwanej Zajączkowska, i kieleckiej zwanej Szydłowiecka ${ }^{60}$. Erekcja klasztoru paulińskiego nastapila 22 czerwca $1472 \mathrm{r}$. Od tej pory parafia na Skałce zarządzali przeorowie konwentu Paulinów. Pierwszym przeorem a zarazem prowincjałem był Jakub z Bogumilowic. W aktach Konsystorza Krakowskiego można odnaleźć niektóre imiona skałecznych przeorów. W 1. 1477-1480 Mikolaj' ${ }^{61}$, 1486-1488 Laurentius ${ }^{62}$, w r. 1487 Blasius $^{63}, 1489$ Stanislaus $^{64}$, w r. 1491 Maciej $^{65}$ i w r. 1499 Stefan $^{66}$.

Trzecia parafia na Kazimierzu została w r. 1405 oddana księżom kanonikom regularnym, mieścila się przy kościele Bożego Ciała. Przelożonym kanonii kazimierskiej i rektorem parafii był Kasper Polak znany z tego, że w r. 1463 zawierał ugodę $\mathrm{z}$ Wachawem, księciem zatorskim, jego żoną Małgorzata i synami Kazimierzem i Wacławem ${ }^{67}$. Po nim rzady objąl nad konwentem i parafia aż do r. $1493^{68}$ Jakub zwany Vadovius. Od r. 1495 aż do r. $1500^{69}$ parafia kierowal prepozyt Andrzej, następnie zaś Piotr, zwany Prowizor ${ }^{70}$. Kościól Bożego Ciała jako fara kazimierska, nie był obciążony opieką nad dobrami poza murami miasta, toteż skupial się glównie na pracy duszpasterskiej na terenie Kazimierza.

Kończąc trzeba zwrócić uwage na parafię leżącą na terenie Zwierzyńca, przy klasztorze Norbertanek. Byla to jedyna w Krakowie parafia związana $\mathrm{z}$ żeńskim klasztorem. Rządy $w$ niej sprawowali prepozyci $\mathrm{z}$ zakonu norbertanów, przeważnie bracia z klasztoru brzeskiego (hebdowskiego), wybierani

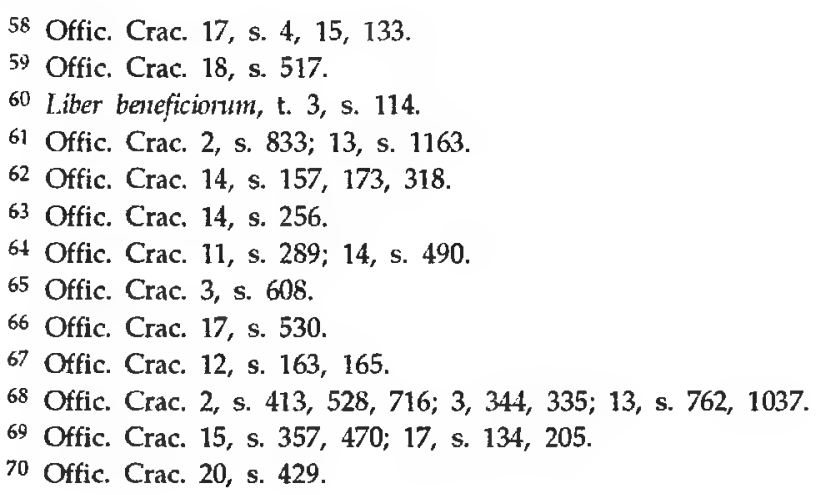


i prezentowani przez ksienię zwierzyniecką. Prepozyt $w$ porozumieniu $z$ ksienią administrowal bogatymi włościami konwentu. Same zakonnice żyjące za ścisłą klauzura oddawały się modlitwie. W ważniejsze święta duchowni premonstratensi brali udział $W$ śpiewach liturgicznych wykonywanych przez zakonnice na zachodniej emporze, siedząc $w$ prezbiterium. Od r. 1473, po prepozycie Wacławie, kierowal parafia przez dwadzieścia lat prepozyt $\operatorname{Piotr}^{7}$. Po nim, na krótko prepozytem zostal Maciej ${ }^{2 / 2}$, na jego miejsce wszedl później Jan Trzciel ${ }^{73}$, profes brzeski, który dotychczas byl kustoszem na Zwierzyńcu, czyli zastępca prepozyta. Lecz i on nie wytrwal długo, odszedl dobrowolnie w r. 1496. Na powrót uczyniono prepozytem Macieja ${ }^{74}$, ale wytrwal tylko rok 1497. Po nim znowu na przeciag jednego roku (1498) stanowisko objal Wawrzyniec (Laurentius) ${ }^{75}$, niegdyś kustosz na Zwierzyńcu i prepozyt $w$ Imbramowicach. Ostatnim ze zwierzynieckich prepozytów w XV w. zostal Jan ${ }^{36}$, który rządzil w l. 1499-1500. Tak częsta zmiana prepozytów musiala wynikać zapewne $\mathrm{z}$ trudnych warunków w klasztorze.

Patrząc na plebanów krakowskich zauważamy, że na czele najlepiej udotowanych parafii stanęli synowie magnaterii polskiej. W parafii Wszystkich Świętych plebanię domus muratae posiadal z prezenty własnej rodziny Jan Feliks Tarnowski kanonik krakowski, w kolegiacie Św. Floriana należącej do Uniwersytetu, gdzie prawo prezentowania na godność prepozyta zastrzeżona była dla króla mianowano Jakuba Koniecpolskiego, syna Jana Taszki z Koniecpola, kanclerza państwa. Po śmierci Jakuba w r. 1481 prepozytem został Grzegorz z Lubrańca, wicekanclerz państwa, również kanonik krakowski.

Często prepozytami zostawali lekarze, jak np. Jan Wels $w$ parafii św. Szczepana (zm. 1497) Andrzej Grzymała z Poznania zarządzający parafią św. Mikolaja (zm. 1466) oraz Stanisław Zelik, doktor medycyny, dziekan nowo zalożonej kolegiaty Wszystkich Świętych. Funkcje zarządzajacych parafia powierzano czlonkom kapituły - byli nimi archiprezbiter parafii Mariackiej, Jan Borzymowski (zm. 1498), Arnolf z Mierzyńca, prepozyt parafii Wszystkich Świętych, mieszkający $w$ drewnianym domu, Mikołaj Wróblewski, prepozyt tejże kolegiaty i św. Jakuba na Kazimierzu, oraz Jan Skałka z Szebni, prepozyt parafii św. Stanisława na Skałce. Ciekawy wydaje się fakt, że wśród plebanów zarządzających krakowskimi parafiami wielu mialo rodowód mieszczański. Byli to archiprezbiterowie mariaccy, Jerzy Sworcz i Jan Heydeck zw. Mirica, profesorowie Univiersytetu, Jan ze Slupcy oraz dwaj Janowie - Beber z Oświęcimia i Sacranus. Także Maciej z Kościana i Bartlomiej ze Żnina

71 Offic. Crac. 2 , s. 515,$630 ; 3$, s. $131,323,486 ; 15$, s. 44,$54 ; 18$, s. $71,121$.

72 Offic. Crac. 15, s. $508 ; 18$, s. 451.

73 Offic. Crac. 18 , s. $451 ; 20$, s. $243,394$.

74 Offic. Crac. 15 , s. $508 ; 17$, s. 386.

75 Offic. Crac. 17 , s. 435,$452 ; 20$, s. $101,106$.

76 Offic. Crac. 19, s. $44 ; 21$, s. 92. 
zarządzający parafią św. Anny, jak również magister Florian, pleban parafii św. Szczepana. Czlonkowie zakonów krakowskich stojacy na czele parafii, Mikolaj z Opawy czy Marcin z Biecza, także byli pochodzenia mieszczańskiego. Natomiast z cala pewnością stwierdzić się da chlopskie pochodzenie Jakuba Rynczy z Batowic, plebana parafii św. Jakuba na Kazimierzu.

Kaplan późnego średniowiecza był to sacerdos beneficiatus. Nie wyobrażano sobie wówczas pracy duszpasterskiej bez posiadania beneficium. Beneficiaci odprawiali msze rzadko, najczęściej przynagleni obowiązkiem fundacyjnym, a i wtedy nierzadko poslugiwali się gracjalistami, tj. kaplanami bez beneficjów, którzy za 12 groszy miesiẹcznie odprawiali msze św. zapisane w erekcji oltarza, trzy razy w tygodniu. Plebani odprawiali msze zwykle tylko raz w tygodniu. Mimo zakazów kościelnych kumulowania beneficjów, praktyka ta była powszechnie stosowana. Nie zważano również na zakaz noszenia broni przez osoby duchowne, noszenie mieczyka zaczynano już od czasów kleryckich. Kapłanów obowiązywala dluga tunika, pod którą należało nosić subductę $w$ ciemnym kolorze, jednak $w$ inwentarzach duchowieństwa często spotykamy szaty kolorowe.

Brewiarz (viaticus) poza klasztorami odprawiano prywatnie. 